\title{
Responsive planning in development interventions: consulting rights-holders in the Sanitized Villages programme in Kongo Central
}

\section{Tine Destrooper}

To cite this article: Tine Destrooper (2016) Responsive planning in development interventions: consulting rights-holders in the Sanitized Villages programme in Kongo Central, Development in Practice, 26:3, 334-345, DOI: 10.1080/09614524.2016.1151479

To link to this article: https://doi.org/10.1080/09614524.2016.1151479

曲 Published online: 05 Apr 2016.

Submit your article to this journal $\pi$

Џلll Article views: 104

View Crossmark data $\complement$ 


\title{
Responsive planning in development interventions: consulting rights-holders in the Sanitized Villages programme in Kongo Central
}

\author{
Tine Destrooper
}

\begin{abstract}
This article empirically examines one of the most important causes of the non-implementation of human rights-based approaches to development (HRBAD): their alleged limited relevance for actors on the ground. The article argues that claims about local relevance can only be made after meaningful consultation with local rights-holders. Consulting local rights-holders in order to ensure responsive planning is not only relevant for HRBADs, but for development interventions more generally. The article presents new material on the Sanitized Villages programme in the Democratic Republic of the Congo to assess whether and how rights-holders are consulted, and identifies four mechanisms that can facilitate meaningful consultation.
\end{abstract}

Cet article examine de manière empirique l'une des causes les plus importantes de la non-mise en œuvre des approches du développement basées sur les droits de l'homme (ADBDH) : sa pertinence présumée limitée pour les acteurs sur le terrain. L'article soutient que les affirmations relatives à la pertinence au niveau local ne peuvent être faites qu'après une consultation véritable des détenteurs de droits. La consultation des détenteurs de droits locaux afin de veiller à une planification réactive est pertinente non seulement pour les $A D B D H$, mais aussi pour les interventions de développement de manière plus générale. Cet article présente de nouveaux supports relatifs au programme Sanitized Villages (villages assainis) mené en République démocratique du Congo pour évaluer si et comment les détenteurs de droits sont consultés, et identifie quatre mécanismes qui peuvent faciliter une consultation véritable.

El presente artículo examina empíricamente una de las causas más importantes para no implementar enfoques basados en los derechos humanos para el desarrollo (HRBAD por sus siglas en inglés): su supuesta pertinencia limitada en el caso de los actores en el terreno. La autora sostiene que las afirmaciones relativas a la pertinencia local solo pueden formularse tras una cuidadosa consulta realizada a los derechohabientes locales. En aras de asegurar la implementación de la planeación flexible, la consulta a esta población reviste importancia para los HRBAD y para otras intervenciones de desarrollo en general. Al respecto, el artículo da cuenta de nueva información surgida del programa de Aldeas Higienizadas implementado en la República Democrática del Congo, que puede ser utilizada para valorar si los derechohabientes son consultados y de qué forma lo son, identificando, además, cuatro mecanismos que podrían facilitar la realización de una consulta significativa.

\section{ARTICLE HISTORY}

Received 12 May 2015

Accepted 26 October 2015

\section{KEYWORDS}

Rights; Aid - Accountability, Capacity development; SubSaharan Africa 


\section{Introduction}

"Where, after all, do universal human rights begin? In small places, close to home; so close and small that they cannot be seen on any map of the world." Eleanor Roosevelt, "In Our Hands" (1958 speech delivered on the tenth anniversary of the Universal Declaration of Human Rights)

Human rights have become the dominant normative conception in the field of development in the last two decades, and have been explicitly incorporated in development programming principles. The human rights-based approach to development (HRBAD) refers to a conceptual framework for the process of human development that is "normatively based on international human rights standards and operationally directed to promoting and protecting human rights" (OHCHR 2006, 15). In this article I do not analyse the broad variety of ways in which human rights and development are linked, but rather the more specific issue of operationalisation of HRBADs. ${ }^{1}$

The 2003 UN Common Understanding on the HRBAD (UN 2003) called on all UN programmes to mainstream the human rights standards contained in the Universal Declaration of Human Rights as a guiding principle, and identified the operational principles of this approach. These principles include meaningful participation of rights-holders, integration of top-down and bottom-up approaches, and local ownership of the development process. While there is no formal obligation to consult rightsholders in the UN Common Understanding of the HRBAD, the references to participation, inclusion, and local ownership implicitly invite for the consultation of rights-holders at various stages of the intervention. There is, moreover, widespread agreement amongst development practitioners and scholars that the voices of rights-holders should be taken into account when planning interventions (see, for example, Nyamu-Musembi 2005; Merry 2006; Gready 2008). From a theoretical point of view, the consultation of rights-holders is a pertinent component of responsive planning. ${ }^{2}$

In academia, the HRBAD has received significant attention because it provides a coherent normative framework for interventions, which focuses on socially and economically disadvantaged groups and which has the potential to repoliticise development and to challenge the structures that lead to inequality (see, for example, Nyamu-Musembi and Cornwall 2004; Gready 2008; Gysler 2012; Gready and Vandenhole 2014).

Despite wide acclaim for the potential of a HRBAD, earlier fieldwork (Russell 2010; Destrooper 2015) showed that many development actors, including those in our case study, are reluctant to structure interventions along the lines of this paradigm, and instead adopt more hands-on paradigms, such as Sanitation Marketing (SanMark) or a Community Approach to Total Sanitation (CATS). ${ }^{3}$ These alternative paradigms are also promoted by higher decision-making levels (see, for example, WaSH 2010; UNICEF 2013a, 2013b), meaning that policy officers often perceive the HRBAD as just one among many priorities to mainstream, rather than as an overarching principle (Uvin 2007; Gysler 2012). Vandenhole and Gready (2014) point out that development practitioners often see human rights as a framework for structural change rather than as a tool for addressing concrete or technical development matters. The assumption of social change that is implicit in a HRBAD can indeed challenge the practical relevance of the approach. Adopting a HRBAD means talking about the relationship between a state and its citizens, and transforms a fairly neutral development discourse into a political process (Uvin 2007; Russell 2010). Development practitioners often argue that they are not in a position to pressure government because they do not have a mandate to do so, and because this would challenge their partnership with government.

In addition to these reasons for non-implementation, policy officers often assume that a HRBAD cannot adequately talk to the concrete realities of rights-holders (Destrooper 2015). Whereas the human rights norms that underlie a HRBAD are universal, development projects, inevitably, are contextual and grounded in local realities. This can lead to problems in the process of translating these universal values and discourses to concrete and contextualised interventions (Gysler 2012). As one of the interviewees in this study argued:

" ... the HRBAD is a very Western concept. Here people do not really understand the difference between the right to water and the need for water. At least, you can't assume they do. Even I find the distinction very abstract and 
difficult, so if you are working with people who have no formal education whatsoever and who live in a country that doesn't really have laws the way we know it, it's really difficult for them to understand what this means."

This interpretation risks equating a rights-based approach with a needs-based approach. The latter was pursued by most UN development agencies before 1997 and consisted of identifying the basic needs of beneficiaries and either supporting initiatives to improve service delivery or advocating for the fulfilment of these needs. This approach, in theory, stands in stark contrast with the rights-based approach in the sense that an unfulfilled need merely leads to dissatisfaction, whereas an unfulfilled right constitutes a violation and empowers the rights-holder to seek - legal - redress or reparation. This means that a rights-based approach also brings duty-bearers and their responsibility into the picture, and endeavours to create a dynamic of accountability, which is not the case under a needs-based approach. Earlier research on the Sanitized Villages programme however showed that there is virtually no attention for the responsibility of duty-bearers, the accountability of development actors, the empowerment of rights-holders to claim their rights, or the potential of a HRBAD to politicise development (Destrooper 2015).

The statement of the UNICEF country officer above, moreover, does not only equate a HRBAD with a needs-based approach, it also suggests that the decision to omit certain elements of a HRBAD such as references to duty-bearers, accountability, and claiming rights - is a matter of responsive planning, because rights-holders expressed no interest in these elements. In this article, I assess whether the decision to implement a scaled-down version of the HRBAD in this case can indeed be interpreted as responsive planning. To do so, I assess whether rights-holders have at all been consulted about their priorities and preferences, and whether the decision to scale down the HRBAD was, as some country officers suggested, based on consultations with local rights-holders. Based on this analysis, I identify four mechanisms that affect the potential to consult rights-holders and to develop a bi-directional, top-down bottom-up, programme.

\section{Theoretical perspective}

This article's concern with local voices is rooted in the very conceptualisation of the HRBAD as a topdown bottom-up approach (UN 2003). The theoretical perspective that captures this bi-directionality is De Feyter's concept of the localisation of human rights (De Feyter, 2006; De Feyter et al. 2011). This perspective conceptualises the bi-directionality inherent in the use and development of human rights norms, and theorises the ways in which human rights norms and development programmes that originate at the transnational level can be translated to the local context, as well as the question of how local voices can be upstreamed to render global human rights and development architecture more reflective of rights-holders' concerns (De Feyter 2006; Oré Aguilar 2011).

This perspective builds on two other actor-centred approaches to human rights. First, the groundbreaking work by Merry on vernacularisation, who argues that for existing human rights norms to become effective, these need to be situated within local contexts of power and meaning by norm-entrepreneurs and implemented on the basis of a vernacularised consensus (see, for example, Merry 2006; Levitt and Merry 2009). Second, the literature on the upstreaming of local human rights concerns, which focuses on the potential of local rights-holders to shape the international human rights architecture (see, for example, De Gaay Fortman 2011). It is precisely De Feyter's proposal to integrate these top-down and bottom-up processes that makes his framework relevant for this article. I use this perspective to explore how the HRBAD can be made relevant for the most disempowered and vulnerable groups.

\section{Case study and fieldwork}

This article uses new empirical material on the Sanitized Villages programme in the Kongo Central province of the Democratic Republic of the Congo to examine whether and how this programme, 
which is formally human rights-based, seeks to engage with voices from below in different stages of the intervention, and whether the input from these consultations was upstreamed and integrated. The Sanitized Villages programme seeks to implement small cost-efficient changes to improve people's access to clean water and to improve sanitation facilities in rural areas. The programme is officially administered by the DRC government. However, in practice, UNICEF plays a dominant role in the decision-making because of its financial and organisational importance. ${ }^{4}$ UNICEF formally adheres to a HRBAD and is supposed to use this as a criterion for selecting its partners, according to Executive Directive 98-04 (also see UNICEF 2012). One could therefore expect to find a HRBAD in this programme. $^{5}$

The article is based on fieldwork in Kongo Central carried out in spring 2012 and on ongoing anthropological fieldwork. Together with a junior researcher and an interpreter, I carried out semistructured qualitative interviews with village elders $(n=9)$, rights-holders $(n=16)$, organisers $(n=$ 3 ), and local health officers in charge of implementing the programme $(n=9)$. These interviews probed for the role which the HRBAD played in planning interventions on the ground. They also gauged gauging how this approach was perceived by rights-holders and implementers. In addition, we carried out observations and organised focus groups in nine villages participating in the Sanitized Villages programme. On the basis of these initial visits, further anthropological fieldwork is being carried out in the coastal district of Kongo Central. Several interviews were also held with experts in Kinshasa and Matadi, the provincial capital. These interviews focused on the strategies and organisational dynamics shaping the interventions. For this article, we interviewed all present members $(n=10)$ of UNICEF's Division for Water, Sanitation and Hygiene (WaSH). This included the programme director, as well as officers in charge of sub-domains such as communication, institutional support, training and development, monitoring and evaluation, partnerships, and emergency interventions. Mid-ranking government officials of the Ministry of Health who were involved in this programme $(n=3)$ and the programme officer of a project partner (SNV) were also interviewed. Interviews with rights-holders were carried out in Kikongo (with the assistance of an interpreter) or French. Expert interviews were carried out in French or English. Names of interviewees and villages are not disclosed, in order to protect the identity of participants in this research.

The next section visibilises the concrete experiences of rights-holders, which are often invisible in official reports. I do not assume these narratives to hold a stronger claim to truth than the narrative in official programme documents, and present them as a complement to the policy documents' narrative. ${ }^{6}$ I use the case of one Sanitized Village, which can be considered representative of other villages in our study. The dynamics that are described here are indicative of more structural processes that were encountered in all villages to some extent. Following this discussion, I present the situation in another village that can be considered an outlier case to identify mechanisms that can foster bi-directionality in the HRBAD. On the basis of this, I reflect on structural provisions that can facilitate the consultation of local actors and the bi-directionality of development interventions.

\section{Navigating between ventriloquism and consultation}

The first village which we visited was presented to us as a success story by the Local Health Officer in charge of the programme. Upon arrival, we were welcomed by villagers and were shown the sanitary infrastructure, that appeared to be in good shape. During the focus group discussion with members of the village committee, respondents initially expressed their satisfaction with how the project had been implemented and with its outcomes. Several villagers concurred that there had been training sessions and consultations before the start of the intervention, and that they had a chance to express their priorities and desires on that occasion. Several respondents also pointed out, in response to our expressed interest in the issue of human rights, that there had been much attention for the issue of rights during these sessions. When my colleague followed the Local Health Officer to visit an installation, I continued the group discussion, trying to better understand the nature and scope of the participation and consultation the group had mentioned. At this point, it became clear that the situation 
in this village was not the success story our respondents told when the Local Health Officer was within hearing distance.

Whereas people had first indicated that the project had been a participative undertaking in which the entire village joined forces, people were considerably more critical about the nature of this participation when they felt they could talk freely. On paper, the entire structure of the Sanitized Villages programme is based on community participation in each step of the programme: communities request to join, select a village committee to ensure local ownership, carry out a situation analysis, develop an action plan, and execute and evaluate that plan (MinSan MinEdu 2011). Yet, in this village, respondents indicate that they never took a decision as a community to join the programme because the Local Health Office signed them up, that they did not develop the intervention plan themselves, that there was never a formal evaluation as far as they knew, and that their only participation consisted of providing manual labour and local material during the execution of the project, which they did not experience as empowering. There was no participation in the strategic decision-making.

The consultation of rights-holders was restricted to a limited number of practical issues, even though consultation of rights-holders is explicitly foreseen in the Sanitized Villages programme (MinSan MinEdu 2011), and even though several WaSH officers suggested that some elements of the HRBAD were not implemented in this case because rights-holders expressed no interest in them. ${ }^{7}$ Initially, villagers indicated that they had been consulted on several occasions; however, these consultations were not frequent and only dealt with practical matters. Respondents moreover indicated that their input was often ignored. ${ }^{8}$ Considering that there were never consultations on strategic matters, UNICEF's claim that rights-holders did not express an interest in the HRBAD is hard to sustain.

So, rights-holders participate in, and are consulted about, certain practical aspects of the interventions of a programme that is otherwise passed on to them in a top-down manner, but there is no platform or phase where they can comment on the overall nature of the interventions or where there is a discussion of more general strategic matters, like the right to water.

When probing what the group referred to when they initially mentioned that the meaning of the right to water had been explained to them, and whether they did not consider that as a discussion on strategic interests, one woman interjected:

"... they told us once that the fact that water is a right, means that water is life, we need water and therefore we have a responsibility for providing it, and they asked us if we understood this ... That's what you mean with informing us about our rights, no?"

The rest of the focus group nodded receptively. "L'eau, c'est la vie [water is life]", the slogan of the national water authority, was used repeatedly from then on, when we asked whether anyone had talked with them about the fact that access to clean drinking water was a right. No one was familiar with the idea of duty-bearers or of claiming a right. The interjection of this woman is moreover indicative of the extent to which the discourse of needs and that of rights are used interchangeably in this programme, thus undermining the specificity of a HRBAD, which lies precisely in the fact that water should not merely be treated as a human need, but also as a human right, which can be claimed from duty-bearers.

The programme structure foresees no explicit phase in which these matters are discussed with rights-holders, nor are there any provisions for rights-holders to have their voices heard on more structural matters. When discussing this with the Local Health Officer, he hinted at the impossibility of implementing this:

\footnotetext{
"You have to look at these people, their level of education, what they need. They need pumps. They need clean water. They need toilets. I don't need to ask them. I know. I am a doctor. I know that village and its needs ... Besides, no one is interested in [talking about rights]. [ ... ] What I am asked is how many pumps we have installed. So that's what we do, we install as many pumps as possible ... In the end, it's only the pumps that matter."
}

This statement is entirely devoid of references to duty-bearers, to claiming rights, or to the participation of rights-holders in all phases of the programme. All of these are however crucial elements of a HRBAD. 
The interviewee furthermore stated that there was no provision to consult rights-holders about their strategic interests or their development priorities regarding the right to water, arguing that people in this situation are not capable of reflecting on these abstract issues. UNICEF country officers seemed to share this interpretation and did not push local health officers to include this kind of consultation, or to facilitate rights-holders' participation in structural decision-making. ${ }^{9}$ The argument that local rights-holders do not spontaneously bring up their strategic interests, or do not talk about water as a right, should not be taken at face value as a lack of interest for a framing that politicises the issue of access to water and that would allow people to take strategic action. It is true that many interviewees in the villages initially had a blind-spot for more structural issues related to the provision of clean drinking water or adequate sanitary infrastructure. However, our fieldwork also showed that people were interested in discussing these issues once they were invited to do so. The decision not to engage with these rights-holders on more structural matters can therefore be seen as a tautological reasoning, and ignores the role programmes like these can play in raising awareness about human rights and about how they can be applied in specific localities.

The fact that this is not happening also means that there is only limited attention to the issue of accountability, another core component of the HRBAD. As the example of the well showed, rightsholders' voices are not always adequately integrated in the programme design and execution, and rights-holders indicated that they had nowhere to go to complain about this. In other villages, interviewees also referred to cases in which their advice had been ignored by the programme coordinators, and to their inability to bring this to anyone's attention. In some villages people mentioned instances of fraud, which went unreported because they had nowhere to go to report this. This hints at a problem with the flow of information, which can be attributed to the lack of sound mechanisms for information sharing. Most rights-holders expressed feeling resigned and powerlessness when discussing how nothing had happened with their suggestions. This points to a structural failure of the programme, whereby there is no obligation for partners to follow-up on, or react to, complaints and claims of rights-holders. The blind spot for the consultation of rights-holders on strategic matters thus also led to a blind spot for the development of mechanisms for sharing information more generally. As a senior Country Officer mentioned:

"If there is a problem, of fraud or whatever, of course we don't meddle in that. The goal is precisely to have government take up its own responsibility, without us constantly interfering."

This statement is indicative of unwillingness on the part of UNICEF to install sounder mechanisms for sharing information that could foster accountability and local ownership, while also ensuring that programmatic information could travel through the system. The absence of such mechanisms interferes with the alleged top-down bottom-up nature of a HRBAD. There are no avenues for local rightsholders to have their voices heard, nor are there sufficient avenues to ensure that content that is produced by the development actor is adequately implemented on the ground.

Local relevance then, in the minds of most interviewees at UNICEF's DRC WaSH office, seemed to refer mainly to the views of local health officers, who were not pushed to consult local rights-holders to gain a better understanding of concerns or to facilitate participation that could lead to a reformulation of the programme. Interviews with UNICEF's country officers confirmed that there had been no intention to consult rights-holders on these issues, and that the only form of consultation that was implicit in the programme dealt with practical matters. In practice however, even these consultations were exiguous, despite their status of a cornerstone of the interventions, and there were no mechanisms to ensure the follow-through of rights-holders' input. Training and interventions were moreover not structured around a human rights discourse and facilitators did not seek to listen to local voices. The assumption that local rights-holders do not find a HRBAD relevant is not based on the voices of these rights-holders but rather on local health officers' and country officers' own impression of the situation. In fact, it would be difficult for local rights-holders to form an opinion about rightsbased interventions at all, since a genuine HRBAD was never implemented. 
This logic was visible in all villages in our study. In other villages too, there had been no discussion on the right to water and sanitation, no involvement of villagers as rights-holders, and no consultation on substantive issues. Rights-holders were not asked to provide input on their priorities regarding the right to water and sanitation, nor about how they envisioned this change, or what type of skills they would need for their own clean water supply.

\section{Identifying the mechanisms for bi-directionality in rights-based development interventions}

The lack of formal mechanisms for ensuring bi-directionality is ascribed by UNICEF to the technical nature of its programme, which renders discussions and interventions based on human rights markedly difficult. Bi-directionality would mean that a HRBAD - as formulated at the level of UNICEF headquarters - is implemented in a consistent manner, and that, at the same time, local voices are upstreamed. This section focuses specifically on the process of including and upstreaming local voices, because this has proven to be particularly challenging in practice. I present the case of a second Sanitized Village that offers several insights as to how consultation on strategic matters can be facilitated in concrete development interventions, and how this consultation can be conceptualised as a first step in the upstreaming process.

In this village, like in many others, the quality of hygienic installations had deteriorated rapidly after the completion of the intervention because people did not feel ownership. Because of how widespread this problem was, UNICEF's WaSH Country Office ordered an assessment of different aspects of the programme in 2013. The Dutch Technical Cooperation (Stichting Nederlandse Vrijwilligers, SNV) was one of the partners involved in this assessment, and carried out a pilot project on the issue of ownership in this specific village.

During the SNV's first visit to this village, people were sitting outdoors in a circle made of plastic chairs, and the SNV facilitator sat with them in the circle - unlike most local health officers whom we had seen addressing the group as a teacher. The facilitator talked with people, rather than to people, and overall villagers were doing most of the talking. When discussing this with the interviewee, the facilitator referred to a background and training in social work, and to the importance of always trying to keep discussions as informal as possible and of not acting as an omniscient teacher. The formal goal of the visit was to assess how local ownership of the sanitation infrastructure could be improved. Formally, there was no goal of making the process more human rights-based, only a more practical concern with ensuring that infrastructure worked and would be maintained. Nevertheless, the fact that rights-holders perceived this as a space to talk freely, encouraged them to also address issues that went beyond their immediate needs.

This is an important finding in itself, considering the argument of UNICEF and the Local Health Officers that there was no interest from rights-holders to look beyond their immediate needs. If this group only cared about their immediate practical needs, the discussion would have been dominated by the lack of resources that interfered with their capacity to maintain the infrastructure and take ownership. However, while acknowledging the importance of this problem, the group also spontaneously referred to the responsibility of others - both the state and UNICEF - to foresee these resources. Rights-holders further insisted that they should be able to communicate with these duty-bearers, but that, in order to make their case, they needed both access to relevant partners and skills to develop a good argument. ${ }^{10}$ These people insisted that they wanted to learn to write formal letters, and to formulate convincing arguments in order to be able to negotiate and make their case for material support. This kind of participation in the process is currently not in place. People asked to participate in their own interest representation, and not merely in the practical execution of projects. More specifically, they see these practical interventions as occasions for raising awareness and where they could acquire strategic skills that would help them to take action. In the absence of these skills, rights-holders felt entirely dependent on other actors. As one woman argued, this dependency leaves the project and the rights-holders more vulnerable 
because there is no way for rights-holders to take action, to demand resources, or even to receive protection against abuse of power by the Local Health Office. Thus, rights-holders themselves identified a lack of relevant skills and a lack of access to decision-makers, rather than a lack of resources, as the fundamental causes of a lagging ownership.

This consultation shows that people desired to look beyond their immediate and practical needs, and that they valued meaningful participation, in order to work for structural change themselves and to take ownership. Installing this type of meaningful participation of rights-holders is not just a matter of ensuring the implementation of paradigms that are developed at the transnational level. Because this type of participation seeks to support rights-holders in amplifying their own voice, it can also be a way for practitioners to obtain information about the priorities of actors on the ground, and thus, of facilitating bi-directionality.

Rights-holders' interest in this kind of participation became clear through an open-ended consultation, and would not have surfaced so explicitly if it were not for the SNV intervention. Because of the importance of obtaining this kind of information on the priorities of rights-holders, I explore below the factors that can facilitate this type of open-ended consultation. When comparing the SNV intervention with those in standard Sanitized Villages, four differences stand out. Three are related to the question of how to solicit relevant information, the fourth to how to upstream this content.

First, the interpersonal skills of the SNV facilitator played a crucial role. While this officer did not receive specific training on the job regarding the facilitation of open-ended consultations, he referred to a background and training in social work to explain why it is easier for some people to facilitate this kind of intervention that genuinely listens to rights-holders and that seeks to implement the kind of participatory structures that can foster both awareness-raising on the side of rights-holders and a better understanding of local needs on the side of implementers. All local health officers and their assistants that were interviewed were originally from the region, but received no training on how to organise this type of intervention. As doctors, many of these local health officers moreover had the kind of social status that did not easily accommodate a consultation 'between equals'. This suggests that interpersonal skills are more relevant in this context than familiarity with the local context. Intervening in a non-authoritative manner to enable people to share their views and experiences is a skill that often receives too little emphasis in development programmes. In the case of the UNICEF country officers, interviewees indicated that they had not received this type of training, and that this was not explicitly foreseen for implementing partners neither. ${ }^{11}$

Second, the consultation of rights-holders, which is a crucial element to ensure responsive planning, is often not included in terms of resources in any phase of the intervention. As the SNV officer argued, this case was different, in the sense that the SNV intervention was seen as a last resort:

"You see, the thing is that, they [UNICEF] really didn't know what to do to improve the situation. There had been studies of various kinds, including an anthropological study, which was very insightful, but our task was really to talk to these people and see how we could get them on board, to find out what they wanted."

This suggests that there was no expected immediate material deliverable in this case, and that there was room to engage in discussions on structural, cultural, and material elements that kept people from taking local ownership. Planning the resources and time for this in the programming phase thus seems crucial. However, neither adequate skills training nor time and resources for consultation are prioritised in practice due to the existence of competing paradigms - such as resultsbased management - that do not prioritise the consultation or participation of rights-holders. Practitioners often experience great difficulty when seeking to organise consultations, as these cannot easily be measured or quantified. This problem is most visible in the fact that country officers are not required by headquarters to report specifically on the HRBAD in their annual reports, which address measurable outcomes rather than processes (Destrooper 2015).

This is related to a third factor which can foster the process of listening to local voices, which is the format and timing of consultations. Considering that the UN Common Understanding of a HRBAD 
(UN 2003) stresses local ownership and top-down bottom-up processes, and that the specific programme structure of the Sanitized Village is explicitly based on the participation and consultation of local rights-holders, consultation should be mainstreamed throughout every step of the intervention. Consulting rights-holders as an add-on at the start of the programme (when they do not yet have much information) or only after the interventions (when their advice can no longer have immediate effect), is insufficient in this context. However, a more permanent form of consultation is organisationally and logistically complex to implement. Alternative avenues to mainstream consultation should therefore be developed. The intervention of the SNV suggested that meaningful participation in every step of the programme can also be used as a means for consulting rightsholders. Through meaningful and free participation in each step of the programme, rights-holders feel more empowered and learn to express their preferences about practical matters, which can also lead to their involvement on work for strategic interests (see, for example, Franceschet 2004). While it is true that the organisation of formal consultations might not be directly relevant for technical interventions, these interventions have a focus on participation in any case, and by revisiting the ways in which participation is organised, more attention for the priorities and frameworks of local rights-holders is possible. This in turn can foster local ownership and bi-directionality. To facilitate this, deliverables should be formulated in terms of process, rather than outcome, which requires a rethinking of the principles of results-based management. The pilot case of the SNV shows that if these three factors are in place, it is possible to generate relevant content that constitutes interesting input for development actors at other levels.

There is however a fourth element that needs to be in place to ensure that input that is generated during these consultations can impact on future programming, namely the existence of adequate mechanisms for information sharing. With regards to this, the SNV intervention is compelling. No adequate communications existed in the other Sanitized Villages, yet in the case of the SNV intervention, the SNV, upon the request of villagers, had organised a meeting between committee presidents of several villages, local health officers and their assistants, and local government officials to give rights-holders an opportunity to express their concerns and to foster accountability. Interestingly, UNICEF country officers did not attend this meeting. So even in the most progressive case, there were no structures for rights-holders to have their voices heard by UNICEF. In this sense, the current architecture of the programme not only ignores local voices, but structurally excludes them. As one senior UNICEF interviewee replied when asked about the systematic upstreaming of local concerns, "We don't have the intention to talk to the villagers, of course we do not foresee mechanisms for this. We are only here to support government. ${ }^{\prime 12}$ The idea was that UNICEF was only a technical supporter of government and did not want to or need to be involved in the consultation of rights-holders. Little adaptation to local sensitivities can be expected in the absence of such mechanisms.

The fieldwork thus showed that the SNV was capable of consulting local rights-holders in an openended manner - in the framework of practical interventions - because the personal skills, time and resources, and structural mechanisms for consultation through participation were all in place. The fieldwork also suggests that this contextualisation of the rights discourse can happen in the framework of practical interventions. With regards to upstreaming however, problems persisted, because of the absence of mechanisms for systematically upstreaming input from below, and because there is no obligation for UNICEF - or other partners - to react to claims of rights-holders. Several UNICEF country officers and local health officers argued that it was not necessary to install such mechanisms, or even to organise consultations, because no substantial input on strategic issues could be expected from rightsholders with overall low levels of formal education, and because local health officers allegedly knew local sensitivities. ${ }^{13}$ The SNV case showed however that rights-holders are capable of, and interested in, a nuanced situation analysis and solutions that are relevant for them. These rights-holders' focus on duty-bearers, access, and making demands, can moreover be read in light of the HRBAD's promise to address structural causes of rights violations. This suggests that the HRBAD might have more local resonance than UNICEF officers claimed, and that implementing a HRBAD in a systematic manner could give people additional leverage and imbue their claims with more legitimacy. 


\section{Discussion and conclusion}

There is a growing consensus in literature and amongst practitioners that engaging with local dutybearers is a necessary first step towards beneficial and lasting social change (De Feyter 2006; Merry 2006; OHCHR 2006). Our fieldwork showed that this is not systematically taking place in this case. The decision of UNICEF to omit certain elements of a HRBAD - such as references to rights-holders, accountability, bi-directionality - was allegedly based on the preferences of rights-holders and the non-relevance of these elements in the local context. This article showed that the assessment of local relevance and the subsequent decision to implement this scaled-down version of the HRBAD was based on a top-down assessment of the situation rather than on rights-holders' own assessment.

Moreover, this scaled-down HRBAD did not increase the local relevance of the programme. The Sanitized Villages programme is indeed perceived by many rights-holders as heteronomous. However, this seems to be due to the lack of bi-directionality, rather than to the HRBAD as such a genuine HRBAD has never really been implemented because of operational challenges. The decision to label the programme as a HRBAD, but to structure actual interventions around alternative paradigms such as CATS or SanMark, seems ineffective. There is no indication that these paradigms will be more locally relevant since they too are developed top-down, and since there are no mechanisms to foster bi-directionality or localization in these paradigms neither. ${ }^{14}$ Moreover, equating a HRBAD with a market-based or community-based approach hollows out the meaning of the HRBAD, as well as the very meaning of human rights (Russell 2010).

The intervention of the SNV showed that service delivery and the empowerment of rights-holders are not irreconcilable and that it is possible for development actors to proceed through genuine human rights-based processes when pursuing practical goals, even when contextual factors are not conducive. The SNV intervention showed that non-authoritative consultation on strategic concerns is possible if there is attention for adequate training of facilitators, if there are resources and time for this, and if this is mainstreamed in all phases of the process by means of meaningful participation that prepares rights-holders for thinking about their strategic interests. Where these three factors were in place, rights-holders proposed a genuinely nuanced view regarding the realisation of their right to water and regarding the strategies needed to achieve this. This information is potentially relevant to upstream to development practitioners. In specific, rights-holders requested access to decision-makers and the kind of skills training that would allow them to make proposals for structural change. They themselves thus underlined the need for more meaningful participation. The consultation suggested that rightsholders in fact had several requests that overlap with the logic of a HRBAD, and that, therefore, a HRBAD should not be considered irrelevant in concrete technical interventions. However, in this case too, there were problems with the upstreaming and sharing of these concerns, meaning that the top-down bottom-up synergy proposed by the common understanding remains absent (UN 2003).

If UNICEF seeks to develop its interventions in line with its own organisational guidelines, specifically Executive Directive 98-04, and article 45 of the Convention on the Rights of the Child, there should be genuine efforts to implement a HRBAD in a way which is relevant for rights-holders, and there should be more attention to amplifying the voices of rights-holders in all phases of the programme, in particular at key moments when rights-holders' strategic interests are at stake. ${ }^{15}$ For this to happen, four elements that are currently not systematically prioritised should be mainstreamed. While UNICEF is a decentralised structure, an important share of the responsibility for facilitating this also lies with headquarters, which can demand accountability for these elements from its country offices in the annual reports, and which should foresee adequate resources for this. In the absence of efforts to work on these four domains, local voices risk being further excluded systematically.

\section{Notes}

1. For a general overview, see Andreassen and Crawford (2013); Gready and Vandenhole (2014); Gready and Ensor (2005); Hickey and Mitlin (2009); and Gauri and Gloppen (2012). 
2. Although participation in the Common Understanding refers to the broadest possible process of including rightsholders, there are several ways in which participation can be conceptualised and implemented to facilitate consultation. While both participation and consultation of local rights-holders are pinned on the assumption that the input of these rights-holders is valuable, neither is empowering in itself, and there is no simple causal relation between both terms.

3. SanMark approaches see water and sanitation as commodities in a market and limit the role of development actors to facilitating the free flow of goods in the market. CATS lay the main responsibility for water and sanitation with the community, without addressing structural or political inequalities.

4. Government contributes less than $1 \%$ of the programme funding. The rest comes from bilateral aid, largely coordinated by UNICEF.

5. UNICEF was one of the first UN programmes to formally adopt this approach in 1998, with Executive Directive 98-04. This sets out how human rights norms will henceforth inspire every intervention. A rhetorical adherence to a HRBA can be observed at all levels of UNICEF and is more explicitly present in the discourse of UNICEF than in many other organisations (Russell 2010; Gysler 2012). UNICEF, together with UNDP, was one of the first to operationalise HRBA (Nyamu-Musembi 2004; Russell 2010; Gysler 2012).

6. When we speak of 'local voices' or 'voices from below', we reject an understanding that places the global above the local or that sees local constituencies as uniform and static units organised around a shared culture. We argue that local realities can be a fertile ground for promoting human rights and development, but that it is the interplay between the transnational process and the practices of local users, which in the end holds the potential of making universal human rights norms and development programmes relevant for users.

7. The programme documents foresee that the village committee takes the lead in each step of the intervention, which implies that they should be consulted by the Local Health Office and technical assistants, especially in the early phase.

8. One interviewee reported that the village committee had warned the engineers not to construct the well on the southern side of the village, because of floods in the rainy season, but that this advice had been ignored, meaning that the current well is not operational for several months every year.

9. It should also be noted that local health officers usually are medical professionals, with little experience in the organising inclusive consultation processes, and that they are not trained on this in the framework of the Sanitized Villages programme.

10. The notion of duty-bearers is absent as such, but the meaning of 'responsible' overlaps largely with that of dutybearers in international law.

11. Previous research also showed that officers do not receive specific training on the implementation of a HRBA or on human rights issues more generally, and that there are only few hands-on implementation tools regarding these issues (Russell 2010; Destrooper 2015).

12. While this officer was more explicit about this issue than other interviewees, the officer seemed to voice what other interviewees were also hinting at.

13. Note that such upstreaming mechanisms did exist for practical concerns. For example, the U-Report system was an SMS service installed in the Sanitized Villages, which gave villagers the opportunity to flag problems with sanitation, like the outbreaks of diseases. These mechanisms could be used as blueprint for mechanisms for upstreaming input on strategic matters.

14. This article does not argue that HRBADs are more valuable than alternative paradigms such as the CATS as such, but takes issue with the rhetorical inflation of the HRBAD to an extent where it comes to mean very little, and with the introduction of new paradigms which have also been developed top-down and which are, as such, equally out of touch with local realities.

15. This is irrespective of the direct human rights obligations which UNICEF is considered to have. See Nyamu-Musembi (2004) and Uvin (2007).

\section{Acknowledgements}

The author is thankful to Lesley Turnbull and Jennifer E. Telesca for comments on earlier drafts of this article.

\section{Disclosure statement}

No potential conflict of interest was reported by the author.

\section{Funding}

The fieldwork for this research was funded by the Interuniversity Attraction Poles Programme initiated by the Belgian Science Policy Office, specifically the IAP “The Global Challenge of Human Rights Integration: Towards a Users' Perspective" (www.hrintegration.be). 


\section{Notes on contributor}

Tine Destrooper is the Managing Director of the Center for Human Rights and Global Justice at NYU's School of Law. She is also a post-doctoral researcher at the University of Antwerp. She obtained her PhD at the European University Institute, where she studied the strategies of social movements in post-conflict countries in Central America. Currently she is publishing on the topic of human rights from below, with a focus on gender and development.

\section{References}

Andreassen, B-A., and G. Crawford. 2013. Human Rights, Power and Civic Action: Comparative Analyses of Struggles for Rights in Developing Societies. Abingdon: Routledge.

De Feyter, K. 2006. "Localizing Human Rights". Discussion Paper 2006/2. Antwerp: Institute of Development Policy and Management.

De Feyter, K., S. Parmentier, C. Timmerman, and G. Ulrich, eds. 2011. The Local Relevance of Human rights. Cambridge: Cambridge University Press.

De Gaay Fortman, B. 2011. Political Economy of Human Rights: The Quest for Relevance and Realization. New York: Routledge.

Destrooper, T. 2015. "An Analysis of the Human Rights-based Approach to Development. UNICEF's Role in the Village Assainis Program in the Bas-Congo." In The Global Challenge of Human Rights Integration. Towards a Users' Perspective, edited by K. De Feyter and E. Desmet. Antwerp: Antwerp University Press.

Franceschet, S. 2004. "Explaining Social Movement Outcomes: Collective Action Frames and Strategic Choices in Firstand Second-Wave Feminism in Chile." Comparative Political Studies 37 (5): 499-530.

Gauri, V., and S. Gloppen. 2012. "Human Rights-based Approaches to Development: Concepts, Evidence, and Policy." Polity 44 (4): 485-503.

Gready, P. 2008. "Rights-based Approaches to Development: What is the Value-added?" Development in Practice 18 (6): 735-747.

Gready, P., and J. Ensor. 2005. Reinventing Development? : Translating Rights-based Approaches from Theory into Practice. London: Zed Books.

Gready, P., and W. Vandenhole. 2014. Human Rights and Development in the New Millennium : Towards a Theory of Change. London: Routledge.

Gysler, M. 2012. "Strengths and Challenges of a Human Rights-based Approach to Programming in the Water and Sanitation Sector." Discussion Paper NADEL MAS Cycle 2010-2012.

Hickey, S., and D. Mitlin. 2009. Rights-based Approaches to Development : Exploring the Potential and Pitfalls. Sterling, VA: Kumarian Press.

Levitt, P., and S. E. Merry. 2009. "Vernacularization on the Ground: Local Uses of Global Women's Rights in Peru, China, India and the United States." Global Networks 9 (4): 441-461.

MinSan MinEdu - Ministère de la Santé Publique et Ministère de l'Enseignement. 2011. Atlas. Kinshasa: Ministère de la Santé Publique et Ministère de l'Enseignement.

Merry, S. E. 2006. Human Rights and Gender Violence: Translating International Law into Local Justice. Chicago: University of Chicago Press.

Nyamu-Musembi, C. 2005. "An Actor-oriented Approach to Rights in Development." IDS Bulletin 36 (1): 41-51.

Nyamu-Musembi, C., and A. Cornwall. 2004. What is the Rights Based Approach all about? Perspectives from International Development Agencies Institute of Development Studies. Brighton: Institute of Development Studies.

OHCHR. 2006. Frequently Asked Questions on a Human Rights-based Approach to Development Cooperation. New York: $\mathrm{OHCHR}$.

Oré Aguilar, G. 2011. "The Local Relevance of Human Rights: A Methodological Approach." In The Local Relevance of Human Rights, edited by K. De Feyter, S. Parmentier, C. Timmerman, and G. Ulrich, 109-146. Cambridge: Cambridge University Press.

Russell, A. 2010. "International Organizations and Human Rights: Realizing, Resisting or Repackaging the Right to Water?." Journal of Human Rights 9 (1): 1-23.

U.N. (United Nations). 2003. "The Human Rights-Based Approach to Development Cooperation. Towards a Common Understanding among UN Agencies." Interagency Workshop on a Human Rights-Based Approach.

UNICEF - United Nations Children's Fund. 2012. "Global Evaluation of the Application of the Human Rights-based Approach to UNICEF Programming." New York: United Nations Children's Fund.

UNICEF - United Nations Children's Fund. 2013a. "Analysis of the Medium-term Strategic Plan 2006-2013. A Data and Results Companion to the End of Cycle Review." New York: Unicef.

UNICEF - United Nations Children's Fund. 2013b. "Revised Evaluation Policy of Unicef".

Uvin, P. 2007. "From the Right to Development to the Rights-Based Approach: How 'Human Rights' Entered Development." Development in Practice 17 (4/5): 597-606.

Vandenhole, W., and P. Gready. 2014. "Failures and Successes of Human Rights-Based Approaches to Development: Towards a Change Perspective." Nordic Journal of Human Rights 32 (4): 291-311.

WaSH - Unicef Division for Water Sanitation and Hygiene. 2010. "Sanitation Marketing in a CATS Context: A Discussion Paper." New York: Unicef. 